\section{Plasmina autóloga intravítrea sin asociar vitrectomía. Vitreolisis farmacológica, método perfeccionado con uroquinasa}

Intravitreal autologous plasmin without associated-vitrectomy. Pharmacological vitreolysis, a perfeccionated method using urokinase

\section{Sr. Director,}

La vitreolisis farmacológica, también conocida como vitrectomía enzimática, utilizando plasmina autóloga, ha sido utilizada como co-adyuvante durante la vitrectomía quirúrgica para favorecer el pelado de la interfase vitreorretinal en patologías como el agujero macular, las membranas epirretinianas maculares, la vitreorretinopatía proliferante en el curso de la retinopatía del prematuro, la retinopatía diabética proliferante y/o el desprendimiento de retina traccional (1). Uno de los principales problemas para su uso era su sofisticada técnica de preparación asequible sólo a equipamientos hematológicos de élite.

Recientemente diversos autores han publicado un método simplificado, sencillo, barato y rápido de preparación en el propio quirófano de Oftalmología, de manera inmediata antes de la inyección, utilizando como activador enzimático de la plasmina la estreptoquinasa (2,3). Además, dicha técnica resulta muy eficaz como inyección intravítrea única, sin asociar vitrectomía quirúrgica, en los edemas maculares diabéticos tanto como tratamiento inicial como en casos resistentes a toda terapia (láser, trimacinolona y antiVegf intravítreos) antes de intentar la vitrectomía quirúrgica (Díaz-Llopis $\mathrm{M}$ et al. Intravitreal plasmin without associated-vitrectomy as a treatment for refractory diabetic macular edema. Eye 2008, in press). Tras haber ensayado dicha técnica en más de 30 casos de diversas patologías hemos observado cómo la preparación de plasmina con estreptoquinasa produce en todos los casos un enturbiamiento inicial del vítreo que tarda entre 1 y 7 días en resolverse, existiendo ocasionalmente casos de uveítis postinyección muy intensas.

Hemos desarrollado un método alternativo de preparación de plasmina sustituyendo la estreptoquinasa por uroquinasa. Los pasos a seguir son los siguientes: a) Extracción del paciente de $7 \mathrm{ml}$ de sangre en tubo de coagulación, centrifugando la sangre a $4.000 \mathrm{rpm}$ durante 15 minutos. Simultáneamente un vial de uroquinasa (Urokinase Vedim ${ }^{\circledR}$, 100.000 UI, España) es calentado durante 15 minutos a $37^{\circ} \mathrm{C}$. b) A continuación $1,8 \mathrm{ml}$ de plasma se mezclan con $0,2 \mathrm{ml}$ de uroquinasa, agitándolo vigorosamente la mezcla durante otros 2-3 minutos, manteniéndolo posteriormente incubado a $37^{\circ} \mathrm{C}$ hasta su uso. c) Esterilización de la solución por filtrado a través de filtro milipore 0,22 micras, procediendo inmeditamente a su inyección en el ojo en cantidad de $0,2 \mathrm{ml}$, previa generosa paracentesis de cámara anterior para evitar reflujo.

Hemos comprobado mediante esprectofotometría a $405 \mathrm{~nm}$ de absorbancia y utilizando el agente cromofórico HD-NVA-CHA-lys-pN, que la concentración de plasmina es de $1.05 \pm 0,12 \mathrm{UI} / \mathrm{ml}$, lo que es muy similar a la obtenida con el método de activación con estreptoquinasa $(2,4)$; estando la cantidad inyectada —aproximadamente 0,2 UI/0,2 $\mathrm{ml}$ muy por debajo de los niveles tóxicos (3-4 UI) $(1,2)$. Teniendo clínicamente la misma eficacia que la plasmina preparada con estreptoquinasa, y con

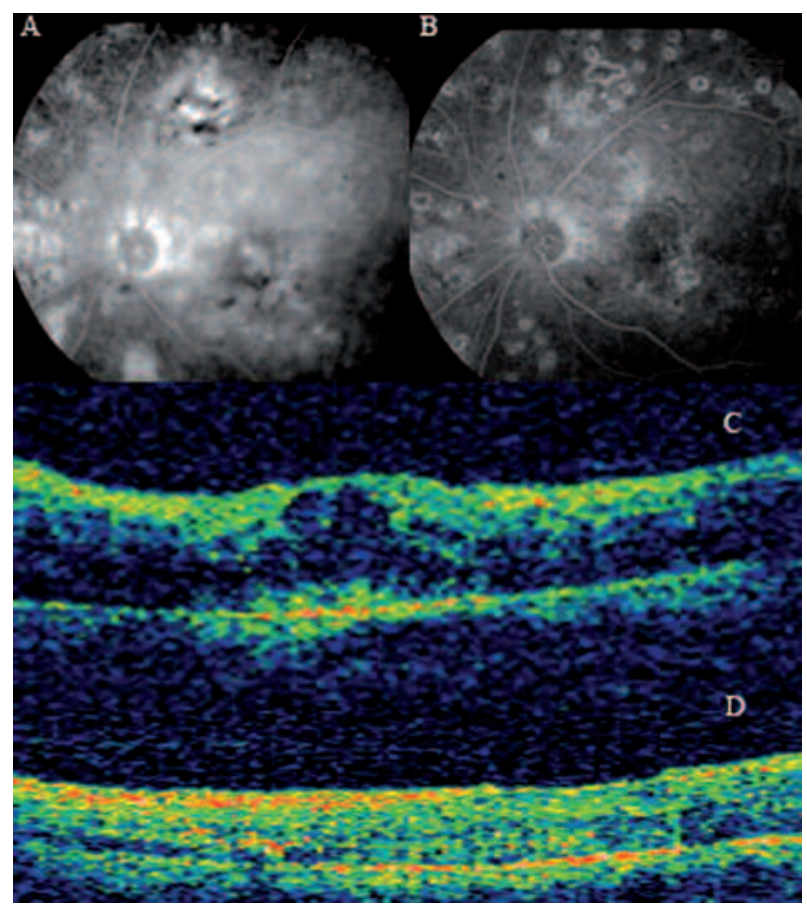

Fig. 1: A y B: Imagen de angiografía antes y después del tratamiento con plasmina en un paciente con edema macular diabético. C y D: imagen de OCT antes y después del tratamiento con plasmina intravítrea en el mismo paciente. 
una experiencia de más de 100 inyecciones realizadas, las grandes ventajas de la preparación de plasmina con uroquinasa son la ausencia absoluta de reacciones inflamatorias adversas intraoculares y el nulo enturbiamiento del vítreo inicial, lo que permite un perfecto seguimiento del fondo de ojo desde el primer momento de la inyección, así como una recuperación más rápida y mejor monitorización de la visión del paciente (fig. 1). Por todo ello creemos que la técnica de preparación de plasmina realizada utilizando uroquinasa debe considerarse de elección para su uso, al menos cuando sea utilizada como tratamiento único intravítreo — sin vitrectomía quirúrgica asociada-.

Díaz-Llopis $\mathrm{M}^{1}$, Udaondo $\mathrm{P}^{2}$, Salom $\mathrm{D}^{2}$, García-Delpech $\mathrm{S}^{3}$, Romero $\mathrm{FJ}^{4}$

${ }^{1}$ Departamento de Oftalmología. Hospital General Universitario Valencia. Facultad de Medicina. Universidad de Valencia. España.

2 Departamento de Oftalmología. Hospital General Universitario Valencia. España.
3 Departamento de Oftalmología. Hospital General Universitario Valencia. Departamento de Farmacología, Neurofisiología y Toxicología. Universidad Cardenal Herrera-CEU. Valencia. España.

4 Departamento de Farmacología, Neurofisiología y Toxicología. Universidad Cardenal HerreraCEU. Valencia. España. E-mail: Manuel.Diaz@uv.es

\section{BIBLIOGRAFÍA}

1. Gandorfer A. Pharmacological vitreolysis. Dev Ophthalmol 2007;39:149-156.

2. Rizzo S, Pellegrini G, Benocci F, Belting C, Baicchi M. Autologous plasmin for pharmacologic vitreolysis prepared 1 hour before surgery. Retina 2006; 26: 792-796.

3. Diaz-Llopis M, Udaondo P, García-Delpech S, Cervera E, Salom D, Quijada A. Vitrectomía Enzimática Por Inyección Intravítrea De Plasmina Autóloga Como Tratamiento Inicial Del Edema Macular Diabético Difuso. Arch Soc Esp Oftalmol 2008; 83: 153-159. 